\title{
SARS-CoV-2 screening testing in schools for children with intellectual and developmental disabilities
}

Michael R. Sherby ${ }^{1 \dagger}$, Tyler J. Walsh ${ }^{2 \dagger}$, Albert M. Lai ${ }^{3}$, Julie A. Neidich ${ }^{4}$, Joyce E. Balls-Berry ${ }^{5}$, Stephanie M. Morris ${ }^{1}$, Richard Head ${ }^{6}$, Christopher G. Prener ${ }^{7}$, Jason G. Newland ${ }^{2}$, Christina A. Gurnett ${ }^{1 *}$ (D) and for the COMPASS-T Study Group

\begin{abstract}
Background: Transmission of SARS-CoV-2 in schools primarily for typically developing children is rare. However, less is known about transmission in schools for children with intellectual and developmental disabilities (IDD), who are often unable to mask or maintain social distancing. The objectives of this study were to determine SARS-CoV-2 positivity and in-school transmission rates using weekly screening tests for school staff and students and describe the concurrent deployment of mitigation strategies in six schools for children with IDD.

Methods: From November 23, 2020, to May, 28, 2021, weekly voluntary screening for SARS-CoV-2 with a high sensitivity molecular-based saliva test was offered to school staff and students. Weekly positivity rates were determined and compared to local healthcare system and undergraduate student screening data. School-based transmission was assessed among participants quarantined for in-school exposure. School administrators completed a standardized survey to assess school mitigation strategies.

Results: A total of 59 students and 416 staff participated. An average of 304 school staff and students were tested per week. Of 7289 tests performed, 21 (0.29\%) new SARS-CoV-2 positive cases were identified. The highest weekly positivity rate was $1.2 \%(n=4)$ across all schools, which was less than community positivity rates. Two cases of inschool transmission were identified, each among staff, representing $2 \%(2 / 103)$ of participants quarantined for inschool exposure. Mitigation strategies included higher than expected student mask compliance, reduced room capacity, and phased reopening.

Conclusions: During 24 weeks that included the peak of the COVID-19 pandemic in winter 2020-21, we found lower rates of SARS-CoV-2 screening test positivity among staff and students of six schools for children with IDD compared to community rates. In-school transmission of SARS-CoV-2 was low among those quarantined for inschool exposure. However, the impact of the emerging SARS-CoV-2 Delta variant on the effectiveness of these proven mitigation strategies remains unknown.
\end{abstract}

\footnotetext{
* Correspondence: gurnettc@wustl.edu

${ }^{\dagger}$ Michael R. Sherby and Tyler J. Walsh contributed equally as co-first authors. 'Department of Neurology, Division of Pediatric and Developmental Neurology, Washington University in St. Louis, 660 S. Euclid Avenue Campus, Box 8111, St. Louis, MO 63110, USA

Full list of author information is available at the end of the article
}

(c) The Author(s). 2021 Open Access This article is licensed under a Creative Commons Attribution 4.0 International License, which permits use, sharing, adaptation, distribution and reproduction in any medium or format, as long as you give appropriate credit to the original author(s) and the source, provide a link to the Creative Commons licence, and indicate if changes were made. The images or other third party material in this article are included in the article's Creative Commons licence, unless indicated otherwise in a credit line to the material. If material is not included in the article's Creative Commons licence and your intended use is not permitted by statutory regulation or exceeds the permitted use, you will need to obtain permission directly from the copyright holder. To view a copy of this licence, visit http://creativecommons.org/licenses/by/4.0/ The Creative Commons Public Domain Dedication waiver (http://creativecommons.org/publicdomain/zero/1.0/) applies to the data made available in this article, unless otherwise stated in a credit line to the data. 
Trial registration: Prior to enrollment, this study was registered at ClinicalTrials.gov on September 25, 2020, identifier NCT04565509, titled Supporting the Health and Well-being of Children with Intellectual and Developmental Disability During COVID-19 Pandemic.

Keywords: SARS-CoV-2 testing, COVID-19, COVID-19 School tests, Children with IDD, Intellectual and developmental disabilities

\section{Background}

In-person school for children with intellectual and developmental disabilities (IDD) provides daily structure, health care services, and therapy, in addition to education. Approximately $14 \%$ of all public-school students have disabilities, which includes students with learning disabilities, speech and language impairment, autism, intellectual disabilities, and emotional disturbance [1]. The American Academy of Pediatrics advocates that inperson learning is particularly important for these children with disabilities due to the additional benefits inperson school provides [2]. During the COVID-19 pandemic, parents/guardians of children with IDD have anecdotally reported being overburdened by taking on additional roles (e.g., physical therapy) that school previously provided. Even pre-pandemic, parents/guardians of children with IDD reported more parenting stress than parents/guardians of typically developing children [3, 4]. Stress can have a compound effect, with challenging child behaviors impacting parental adjustment, which in turn impacts the child's behavior [5]. However, because children with IDD are more vulnerable to severe acute respiratory syndrome coronavirus-2 (SARS-CoV-2) infection [6], with fatality rates reported as high as $1.6 \%$ [7], many parents/guardians have been reluctant for them to resume in-person learning.

Despite the accepted benefits of in-person school, teaching children with IDD presents challenges that could increase the risk of SARS-CoV-2 infection to school staff (teachers, administrators, and staff) and students. Appropriate mask wearing, a foundational school mitigation strategy $[8,9]$, may be challenging for many children with IDD. Many disabled students require assistance with activities of daily living, such as eating, during which social distancing and masking cannot occur. While general recommendations are provided for safe return to school $[10,11]$, specific guidance is unavailable for schools dedicated to children with IDD. Furthermore, since many of these schools remained virtual throughout the pandemic, mitigation strategies specifically targeted to these schools have not yet been evaluated.

SARS-CoV-2 screening is a mitigation strategy recommended by the Centers for Disease Control and Prevention (CDC) when community transmission is moderate, substantial, or high, based on specific thresholds [10].
Literature suggests that screening testing in a typical school setting is unlikely to provide additional benefit even when community transmission is high, based on low rates of school-based SARS-CoV-2 transmission [8, 9, 12]. However, the utility of screening tests in schools for children with IDD, which may be considered highrisk environments for transmission, has not yet been determined.

The objectives of this study were to evaluate the impact of SARS-CoV-2 weekly screening for school staff and students on in-school transmission and describe the concurrent deployment of mitigation strategies in six schools for children with IDD.

\section{Methods \\ Study population}

The study took place at six schools dedicated to children with IDD within the Special School District (SSD) of St. Louis County. SSD provides special education and related services for more than 23,000 students within 22 school districts in St. Louis County. While the vast majority of these students attend school in the district in which they live, 716 children with IDD ages 5-21 years are educated in one of the district's six special education schools. SSD students' medical needs are complex, including 54 students with non-progressive neuromuscular disorder, 8 with progressive neuromuscular disorder, 90 with permanent orthopedic disabilities, 42 receiving gastric-tube feedings, and 11 with tracheostomies. Children who attend these schools are generally bussed from their homes daily. These schools employ 605 teachers, staff, and administrators.

All staff and students were invited to participate in the study, during which weekly saliva samples were collected for SARS-CoV-2 screening testing. Staff, student participants 18 and over, and parent/guardian of students under 18 provided written consent and completed an intake survey of demographic and health data. Here, we report the results of weekly screening of testing starting November 23, 2020, through the end of the school year, May 28, 2021. Student testing did not start until December 11, 2020.

For community level data, we collected ZIP code data from St. Louis City and County public dashboards during the pandemic beginning in early April 2020. Counts were associated with estimated populations for ZIP Code 
Tabulation Areas (ZCTA) to create new case infection rates for 3-month periods. Since the number of cases identified during these periods varies widely, data were converted to quintiles to facilitate comparisons between periods [13].

\section{In-school screening testing}

A highly sensitive PCR-based assay to detect SARSCoV-2 in saliva was developed by Washington University investigators at the McDonnell Genome Institute in partnership with Fluidigm [14]. Each SSD school was assigned a day of the week throughout the study during which samples were collected from participants. Staff predominantly collected their samples at home and submitted them to the study team at a predefined location in the school building prior to the start of the school day. Student collection occurred at the beginning of the school day either in the nurse's office, classroom, or predefined testing location within the school. The study coordinators, with assistance from nurses and teachers, collected the samples from the students. Participants were instructed to submit the test each week even if they had been quarantined, had symptoms, or had tested positive the previous week. For these situations, the tests were collected in the school parking lot. The assay was performed at Washington University's Genome Technology Access Center Cortex laboratory as a CAP/CLIA diagnostic test with clinical oversight by Pathology and Immunology. Results were returned to the participants and the study team on the same day samples were collected. Negative test results were reported by an automated email. Positive results were reported directly to participants by phone from one of the study Principal Investigators (JN).

\section{Evaluation of positive cases}

Staff and students testing positive for SARS-CoV-2 were immediately isolated for at least 10 days, in compliance with the St. Louis County Department of Public Health and SSD human resource policies. All positive participants or their parents/legal guardians were interviewed to determine potential exposures to persons with COVID-19 and to identify potential in-school contacts. Contact tracing was conducted by SSD, as this task was delegated to the schools in St. Louis County due to the high rates of community transmission.

\section{Outcome measures}

The primary outcome was the weekly positivity rate in the six SSD schools. Additionally, we assessed the rate of school-based transmission among the participants who continued testing during their quarantine period. Inschool SARS-CoV-2 transmission was determined by two trained investigators (JN and TW). Data utilized to make this determination included quarantine status, exposure date, diagnosis date, symptom onset, and potential alternative source of transmission (e.g., household contact). When a participant tested positive, the type of transmission was determined by identifying if the participant was currently being quarantined due to a school, household, or community exposure. Additionally, each positive participant underwent a standardized interview by JN to determine onset of symptoms, other potential exposures, and recent high-risk activities. After compiling these data, JN and TW determined if a positive participant transmission occurred in the school, household, community, or was unknown.

\section{School-level data}

Administrators from SSD provided demographic data and completed a standardized survey on the mitigation strategies being implemented at each school. Additional positive SARS-CoV-2 cases among school staff and students not participating in the weekly screening testing were recorded.

\section{Analysis}

We performed descriptive statistics to summarize participant data and school level data utilizing frequencies, percentages, medians, and interquartile ranges. Weekly positivity rates were calculated and aggregated. The school-based secondary transmission rate was calculated among participants.

\section{Results}

The six SSD schools participating in this research study were located throughout St. Louis County (Supplemental Figure 1). The staff and students at the schools varied by race, in-person attendance, and percentage of students receiving free or reduced-price lunch (Table 1). During the first few months of the pandemic from March to June 2020 (see Supplemental Figure 1, inset), the highest rates of COVID-19 cases by quintile occurred in Midtown, North St. Louis City, and North St. Louis County. At study commencement in November 2020, the highest quintile of new cases was in South St. Louis County.

SSD schools returned to optional in-person attendance on November 9, 2020, through a phased re-entry model. During the first 6 weeks of study testing (November 23, 2020 , to January 19, 2021), the schools were in a hybridlearning mode, with half of the in-person students present at school Monday-Tuesday and half on Thursday-Friday each week. Students could also opt for fulltime virtual learning during this period. Starting January 19, 2021, students could attend school in-person fulltime (5 days a week) or opt for full-time virtual learning. At commencement of the study, the lowest in-person student attendance (42\%) was in school 3, and the 
Table 1 Special School District of St. Louis County school demographics and mitigation strategies

\begin{tabular}{|c|c|c|c|c|c|c|c|}
\hline & \multirow{2}{*}{$\begin{array}{l}\text { All } \\
\text { Schools }\end{array}$} & \multicolumn{6}{|l|}{ School } \\
\hline & & $1(9-12+)$ & $2(K-8)$ & $3(9-12+)$ & $4(K-8)$ & $5^{*}(9-12+)$ & $6^{*}(\mathrm{~K}-8)$ \\
\hline Staff employed & 622 & 109 & 105 & 120 & 142 & 70 & 76 \\
\hline Teachers and aids & 466 & 75 & 76 & 95 & 103 & 68 & 49 \\
\hline Administrative staff & 2 & 4 & 4 & 4 & 4 & 5 & 5 \\
\hline Ancillary services & 79 & 9 & 15 & 15 & 16 & 24 & 24 \\
\hline Nurses & 20 & 2 & 7 & 2 & 6 & 3 & 3 \\
\hline Other & 8 & 5 & 3 & 0 & 0 & 0 & 0 \\
\hline Students enrolled (week 14/week 24) & $723 / 656$ & $118 / 95$ & $132 / 128$ & $163 / 132$ & $172 / 173$ & 79/73 & $59 / 55$ \\
\hline Black/African-American & $378(52)$ & $42(36)$ & $69(52)$ & $119(71)$ & $136(79)$ & $5(6)$ & $7(13)$ \\
\hline White Non-Hispanic & $295(41)$ & $72(61)$ & $44(34)$ & $40(24)$ & $32(18)$ & $67(85)$ & $40(73)$ \\
\hline Hispanic/Latino & $20(3)$ & $3(3)$ & $3(2)$ & $5(3)$ & $3(2)$ & $3(4)$ & $3(5)$ \\
\hline Asian & $17(2)$ & $1(1)$ & $10(8)$ & $0(0)$ & $0(0)$ & $3(4)$ & $3(5)$ \\
\hline Other & $10(1)$ & $0(0)$ & $5(4)$ & $0(0)$ & $2(1)$ & $1(1)$ & $2(4)$ \\
\hline In-person/hybrid learning (week 1) & $428(59)$ & $69(59)$ & $83(63)$ & $70(42)$ & $102(58)$ & $54(68)$ & $46(82)$ \\
\hline In-person learning (week 14) & $467(65)$ & $76(64)$ & $93(70)$ & $97(59)$ & $98(57)$ & $61(77)$ & $49(84)$ \\
\hline In-person learning (week 24) & $439(67)$ & $63(66)$ & $90(70)$ & $80(61)$ & $99(57)$ & $61(84)$ & $46(84)$ \\
\hline$\%$ receiving free or reduced lunch & - & $33 \%$ & $100 \%$ & $100 \%$ & $100 \%$ & $27 \%$ & $53 \%$ \\
\hline \multicolumn{8}{|l|}{ Mitigation strategies } \\
\hline$\%$ staff masked & - & $100 \%$ & $100 \%$ & $100 \%$ & $100 \%$ & $>75 \%$ & $>75 \%$ \\
\hline$\%$ students masked & - & $50-75 \%$ & $>75 \%$ & $>75 \%$ & $>75 \%$ & $50-75 \%$ & $50-75 \%$ \\
\hline Desks spaced at least 6 feet in classrooms & - & No & Yes & No & Yes & No & No \\
\hline Symptom screening for students & - & Yes & Yes & Yes & Yes & Yes & Yes \\
\hline Barriers in place & - & Yes & Yes & No & Yes & Yes & Yes \\
\hline Lunch location & - & Class & Class & Class & Class & Class & Class \\
\hline Ventilation system replaced & - & No & No & No & No & No & No \\
\hline
\end{tabular}

Percentages are indicated in parenthesis

*Schools 5 and 6 are in the same building and share the same nurses, ancillary staff, and administrators

highest in-person attendance (82\%) was in school 6 (Table 1). In-person attendance was higher for students in the lower grades.

\section{Study cohort}

A total of 475 participants (416 staff and 59 students) consented to participate in weekly SARS-CoV-2 screening, representing $69 \%$ of eligible staff and $13 \%$ of eligible students. The median age of all staff participants was 44 (IQR 34-53), 84\% were female, and 15\% were Black/African-American (Table 2). Staff participation varied from 57 to $83 \%$ across the schools. The median age of all student participants was 14 (IQR 11-17), 19\% were female, and $24 \%$ were Black/African-American (Table 3). Student participation varied from 6 to $22 \%$ across the schools.

We attempted to test all participants each week. However, adherence to testing among participants decreased over time, from 90 to $63 \%$ of consented participants (excluding week 11, during which a snow storm caused school closures) (Supplemental Figure 2). Each week, an average of approximately $46 \%$ of all SSD staff and $6 \%$ of all SSD students were tested (Supplemental Table 1). Among participants, $12 \%$ provided tests for all 24 weeks and $70 \%$ provided tests for 12 or more weeks.

During the first 24 weeks of the study, we collected and performed 7289 saliva tests (Supplemental Figure 3). A total of 21 participants (19 staff and 2 students) tested newly positive for SARS-CoV-2 (0.29\% of tests performed, excluding repeat positives) (Fig. 1). Following a positive result, the participant's weekly testing continued but any positives within 12 weeks were not counted as new cases (six participants returned repeat positives; one positive had a recent history of vaccination, with the positive test occurring 10 days after the first dose of vaccine was administered). Across the schools, SSD had a median weekly positivity rate of $0.3 \%$ (range 0 to $1.2 \%$ ). Each SSD school had at least one staff member test positive and in only 2 weeks did more than one school have a positive screening test result. All participating SSD 
Table 2 Demographics of staff participants in the 6 Special School District of St. Louis County schools

\begin{tabular}{|c|c|c|c|c|c|c|c|}
\hline & \multirow{2}{*}{$\begin{array}{l}\text { All } \\
\text { schools }\end{array}$} & \multicolumn{6}{|l|}{ School } \\
\hline & & $1(9-12+)$ & $2(K-8)$ & $3(9-12+)$ & $4(K-8)$ & $5(9-12+)$ & $6(\mathrm{~K}-8)$ \\
\hline Staff consented & $416(67 \%)$ & $62(57 \%)$ & 87 (83\%) & $80(67 \%)$ & $94(66 \%)$ & $43(61 \%)$ & $50(66 \%)$ \\
\hline Median age (IQR) & $44(34-55)$ & $43(33-51)$ & $42(33-53)$ & $47(38-55)$ & $42(33-49)$ & $48(36-57)$ & $42(34-51)$ \\
\hline Female (\%) & $348(84)$ & $48(79)$ & $77(89)$ & $64(80)$ & $78(83)$ & $38(88)$ & $43(86)$ \\
\hline \multicolumn{8}{|l|}{ Race/ethnicity } \\
\hline Black/African-American & $62(15)$ & $7(12)$ & $7(8)$ & $23(29)$ & $24(26)$ & $0(0)$ & $1(2)$ \\
\hline White Non-Hispanic & $325(78)$ & $49(80)$ & $75(86)$ & $54(68)$ & $60(64)$ & $41(95)$ & $46(92)$ \\
\hline Asian & $3(1)$ & $0(0)$ & $1(1)$ & $0(0)$ & $1(1)$ & $1(2)$ & $0(0)$ \\
\hline Multiracial & $5(1)$ & $1(2)$ & $2(2)$ & $1(1)$ & $1(1)$ & $0(0)$ & $0(0)$ \\
\hline Other & $3(1)$ & $0(0)$ & $1(1)$ & $0(0)$ & $0(0)$ & $0(0)$ & $2(4)$ \\
\hline Not provided & $17(4)$ & $4(7)$ & $1(1)$ & $2(3)$ & $8(9)$ & $1(2)$ & $1(2)$ \\
\hline \multicolumn{8}{|l|}{ Ethnicity } \\
\hline Hispanic/Latino & $17(4)$ & $3(5)$ & $2(2)$ & $3(4)$ & $3(3)$ & $2(5)$ & $4(8)$ \\
\hline Unknown & $10(2)$ & $0(0)$ & $2(2)$ & $2(3)$ & $3(3)$ & $1(2)$ & $2(4)$ \\
\hline Not provided & $23(6)$ & $5(8)$ & $8(9)$ & $2(3)$ & $5(5)$ & $2(5)$ & $1(2)$ \\
\hline \multicolumn{8}{|l|}{ Staff type } \\
\hline Teacher/teaching assistant & $267(64)$ & $36(58)$ & $55(63)$ & $53(66)$ & $64(68)$ & $29(67)$ & $30(60)$ \\
\hline Administrator/administrative assistant & $16(4)$ & $3(5)$ & $5(6)$ & $4(5)$ & $2(2)$ & $2(5)$ & $2(4)$ \\
\hline Nursing staff & $20(5)$ & $4(7)$ & $5(6)$ & $3(4)$ & $2(2)$ & $5(12)$ & $1(2)$ \\
\hline Ancillary services & $15(4)$ & $1(2)$ & $3(3)$ & $2(3)$ & $4(4)$ & $1(2)$ & $4(8)$ \\
\hline Other & $59(14)$ & $10(16)$ & $11(13)$ & $12(15)$ & $12(13)$ & $3(7)$ & $11(13)$ \\
\hline Not provided & $37(9)$ & $8(13)$ & $8(9)$ & $6(8)$ & $10(11)$ & $3(7)$ & $2(4)$ \\
\hline \multicolumn{8}{|l|}{ Underlying health conditions } \\
\hline None & $170(41)$ & $21(34)$ & $42(48)$ & $30(38)$ & $39(42)$ & $19(44)$ & $19(38)$ \\
\hline At least one & $206(50)$ & $32(53)$ & $36(41)$ & $46(58)$ & $42(45)$ & $22(51)$ & $28(56)$ \\
\hline Two or more & $88(21)$ & $11(18)$ & $16(18)$ & $21(26)$ & $13(26)$ & $8(19)$ & $19(20)$ \\
\hline \multicolumn{8}{|l|}{ Vaccination* } \\
\hline At least one dose & $215(52)$ & $32(53)$ & $51(59)$ & $38(48)$ & $35(37)$ & $29(67)$ & $30(60)$ \\
\hline Fully vaccinated & $235(57)$ & $31(51)$ & $41(47)$ & $46(58)$ & $49(52)$ & 34 (79) & $34(68)$ \\
\hline
\end{tabular}

Percentages are indicated in parenthesis

*As of June 1, 2021

schools remained open, other than the scheduled winter and spring breaks-between weeks $4-5$ and 18, respectively, during which no testing took place. During the course of the study, 36 participants withdrew, representing $9 \%$ of our participants. Reasons for withdrawal varied, from relocating to a different school not included in the study to becoming vaccinated.

To determine whether SSD staff and student positivity was higher than in the community, we compared the participant positivity rate to that of pre-procedure screening tests performed on asymptomatic individuals at BJC Healthcare System in St. Louis during the same period. The SSD participants consistently returned lower weekly positivity rates (0 to $1.2 \%$ ), compared to screening testing at BJC (0.0 to 3.3\%) (Fig. 2) [15].
Furthermore, the SSD positivity rate was comparable to screening of Washington University undergraduate students (Fig. 2). The mean weekly SSD positivity rate was $0.28 \%$ of participants compared to mean weekly screening testing positivity rate at the Danforth Campus of $0.31 \%$.

The 19 staff positives represented $4.6 \%$ of the 416 staff participants who tested at least once during the study. Outside of the study's screening tests, an additional 39 SSD staff and 17 students tested positive via symptomatic or post-exposure diagnostic testing. Inclusive of all positive tests, 77 total SARS-CoV-2 positive cases among staff and students were identified.

During the study period, $18.9 \%$ (39/206) of staff who did not participate in the study's screening tests had a 
Table 3 Demographics of student participants in the 6 special school district of St. Louis County schools

\begin{tabular}{|c|c|c|c|c|c|c|c|}
\hline & \multirow{2}{*}{$\begin{array}{l}\text { All } \\
\text { schools }\end{array}$} & \multicolumn{6}{|l|}{ School } \\
\hline & & $1(9-12+)$ & $2(K-8)$ & $3(9-12+)$ & $4(K-8)$ & $5(9-12+)$ & $6(K-8)$ \\
\hline Students consented & $59(12)$ & $7(10)$ & $12(9)$ & $6(6)$ & $11(11)$ & $12(20)$ & $11(22)$ \\
\hline Median age (IQR) & $14(11-17)$ & $16(15-19)$ & $12(11-13)$ & $18(18-19)$ & $12(11-13)$ & $17(15-18)$ & $12(9-14)$ \\
\hline Female (\%) & $11(19)$ & $1(14)$ & $2(17)$ & $2(33)$ & $2(18)$ & $2(17)$ & $2(18)$ \\
\hline \multicolumn{8}{|c|}{ Student participant race/ethnicity } \\
\hline Black/African-American & $14(24)$ & $0(0)$ & $2(17)$ & $5(83)$ & $7(64)$ & $0(0)$ & $0(0)$ \\
\hline White non-Hispanic & $34(58)$ & $4(57)$ & $7(58)$ & $0(0)$ & $4(36)$ & $10(83)$ & $9(82)$ \\
\hline Asian & $1(2)$ & $0(0)$ & $1(8)$ & $0(0)$ & $0(0)$ & $0(0)$ & $0(0)$ \\
\hline Multiracial & $6(10)$ & $1(14)$ & $2(17)$ & $1(17)$ & $0(0)$ & $1(8)$ & $1(9)$ \\
\hline Other & $1(2)$ & $0(0)$ & $0(0)$ & $0(0)$ & $0(0)$ & $0(0)$ & $1(9)$ \\
\hline Not provided & $3(5)$ & $2(29)$ & $0(0)$ & $0(0)$ & $0(0)$ & $1(8)$ & $0(0)$ \\
\hline \multicolumn{8}{|l|}{ Ethnicity } \\
\hline Hispanic/Latino & $3(5)$ & $0(0)$ & $0(0)$ & $1(17)$ & $0(0)$ & $1(8)$ & $1(9)$ \\
\hline Unknown & $1(2)$ & $1(14)$ & $0(0)$ & $0(0)$ & $0(0)$ & $0(0)$ & $0(0)$ \\
\hline Not provided & $0(0)$ & $0(0)$ & $0(0)$ & $0(0)$ & $0(0)$ & $0(0)$ & $0(0)$ \\
\hline \multicolumn{8}{|c|}{ Underlying health conditions } \\
\hline None & $4(7)$ & $0(0)$ & $0(0)$ & $0(0)$ & $2(18)$ & $2(17)$ & $0(0)$ \\
\hline At least one & $54(92)$ & $7(100)$ & $12(100)$ & $6(100)$ & $8(73)$ & $10(83)$ & $11(100)$ \\
\hline Multiple & $19(32)$ & $2(29)$ & $3(25)$ & $4(67)$ & $3(27)$ & $5(42)$ & $2(18)$ \\
\hline \multicolumn{8}{|l|}{ Vaccination* } \\
\hline At least one dose & $19(32)$ & $5(71)$ & $3(25)$ & $3(50)$ & $1(9)$ & $6(50)$ & $1(9)$ \\
\hline Fully vaccinated & $10(17)$ & $4(57)$ & $0(0)$ & $2(33)$ & $0(0)$ & $4(33)$ & $0(0)$ \\
\hline
\end{tabular}

Percentages are indicated in parenthesis

${ }^{*}$ As of June 1, 2021

positive test, compared with $4.6 \%$ (19/416) of staff who participated during at least one study screening test. Meanwhile, of the non-participant students, 2.6\% (17/ 664) had a positive test result during the study period while $3.3 \%(2 / 59)$ of the participating students had a positive during the same period.

\section{Positive cases}

Among the 19 positive staff participants identified during screening testing, 6 resulted from household transmissions, 6 were likely community-based transmissions from attending large gatherings, such as parties, indoor sporting events, and group exercise, and 5 were from other outside-school transmissions (e.g., during vacation). One positive case had both a household exposure (spouse) and an in-school exposure. Only one case was definitively associated with an in-school exposure. During the study period, 103 participants were tested during a quarantine for an in-school exposure and 2 positives (including the participant with both household and school-based exposure) were identified, suggesting a transmission rate of $2 \%$ or less. The two participants with possible in-school transmission reported reliably masking and maintaining hand hygiene, but did not wear eye protection. An additional 39 staff members and 17 students tested positive outside of the study, but data were not available to determine if in-school transmission occurred.

Of the 2 positive students in the study, no direct exposures were identified. The first student's only outside household exposure was attending school. The second student had been to different households, though an epidemiologic link with an ill family member was not identified.

\section{Mitigation strategies}

Aside from the study's screening tests, masks were mandated and administrators at all 6 schools estimated that $75-100 \%$ of staff reliably masked (Table 1). Prior to returning to school, SSD staff reported a widely held assumption that masking would be particularly difficult for children with IDD. However, students were more consistent at wearing masks than expected. For students, masking was initially estimated to be above $50 \%$ in all schools. In follow-up discussions near the end of the school year, school staff estimated that the overall rate of mask compliance for students was $70 \%$. The staff reported that masks presented the greatest challenge for 


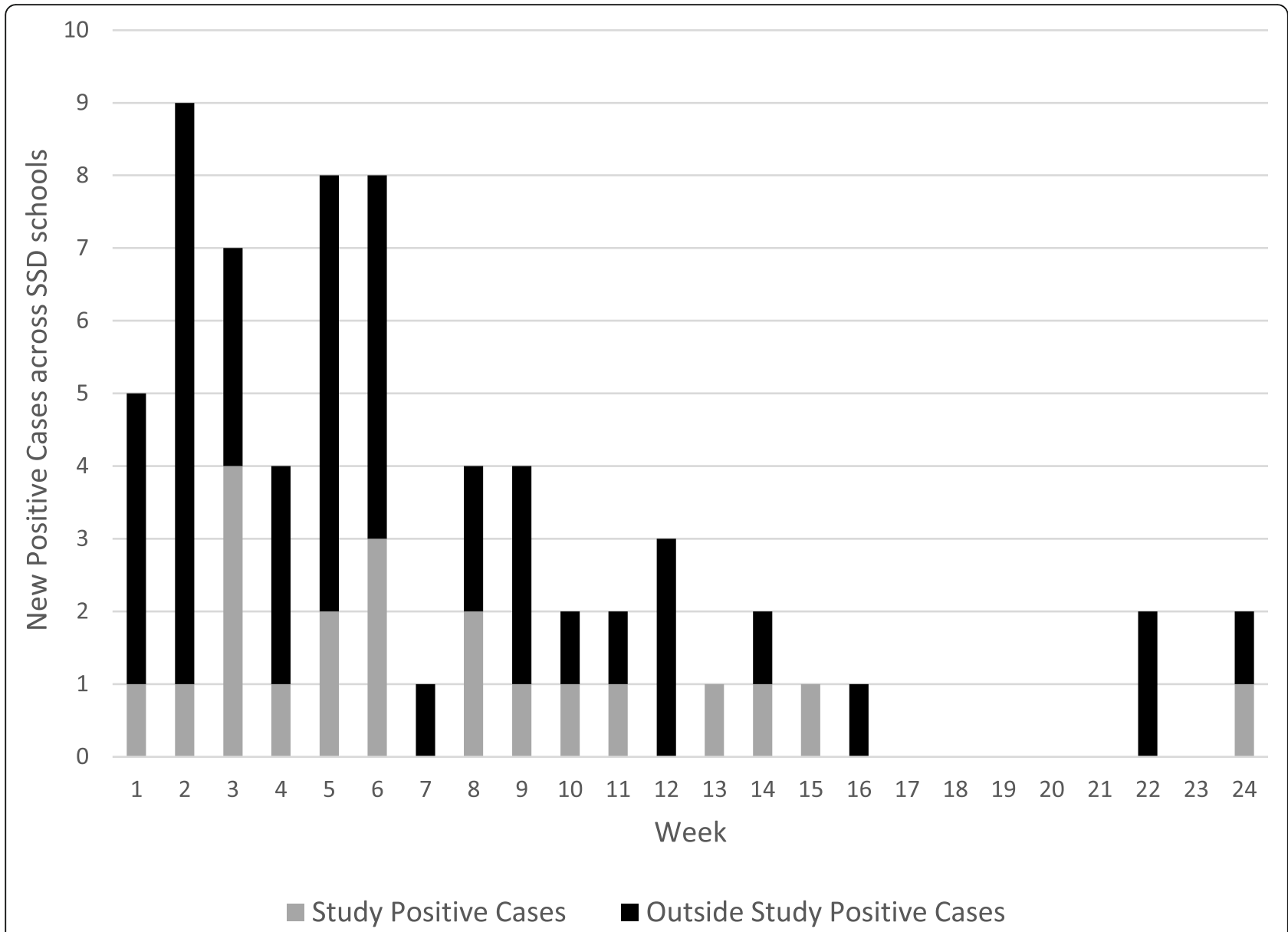

Fig. 1 New positive SARS-CoV-2 cases at SSD schools. Shown are number of new positive SARS-CoV-2 cases detected by study weekly screening tests (gray) and new positive SARS-CoV-2 cases detected outside the study through diagnostic testing (black)

students with severe autism, many of whom were rarely able to mask. However, students often responded to continued mask re-enforcement, modeling, and instruction. When students cannot mask consistently, many SSD staff adopted alternatives, including eye protection by students and staff, hand wipes, and adequate room ventilation. Most classrooms allowed students to be spaced at least six feet apart. Ventilation systems were not changed, though schools reported opening windows when possible.

Additional mitigation strategies cited by SSD included the following: implementation of a phased re-entry plan with a gradual transition from hybrid to full-time inperson learning; provision of sufficient personal protective equipment (e.g., masks, gloves, face shields, and hand wipes); reduction of student movement within school; reduction of class sizes to 5-8 students when possible; cleaning between students and maintaining a sanitation schedule for common areas; frequent use of hand wipes for students unable to wash hands; and demonstration of a firm commitment to safety from the highest level of administration, which required canceling or postponing more risky activities (e.g., potlucks, and other indoor gatherings).

Finally, vaccinations became available for staff and students during the study. At each test, participants were asked to provide their vaccination status, dose date(s), and manufacturer. Of all staff participants, $260(63 \%)$ reported receiving at least a first vaccine dose, 235 (56\%) a complete vaccine course, and 147 (35\%) no vaccination. Students under 16 became eligible to receive the Pfizer vaccine on week 22, and of student participants, 19 (32\%) reported receiving at least a first dose.

\section{Discussion}

This study presents the first SARS-CoV-2 screening testing data for students and staff at schools for children with IDD and the use of mitigation strategies to aid the safe reopening of these schools. Throughout the study, which included the COVID-19 pandemic peak, we found no evidence for increased SARS-CoV-2 positivity rates at schools for children with IDD compared to 


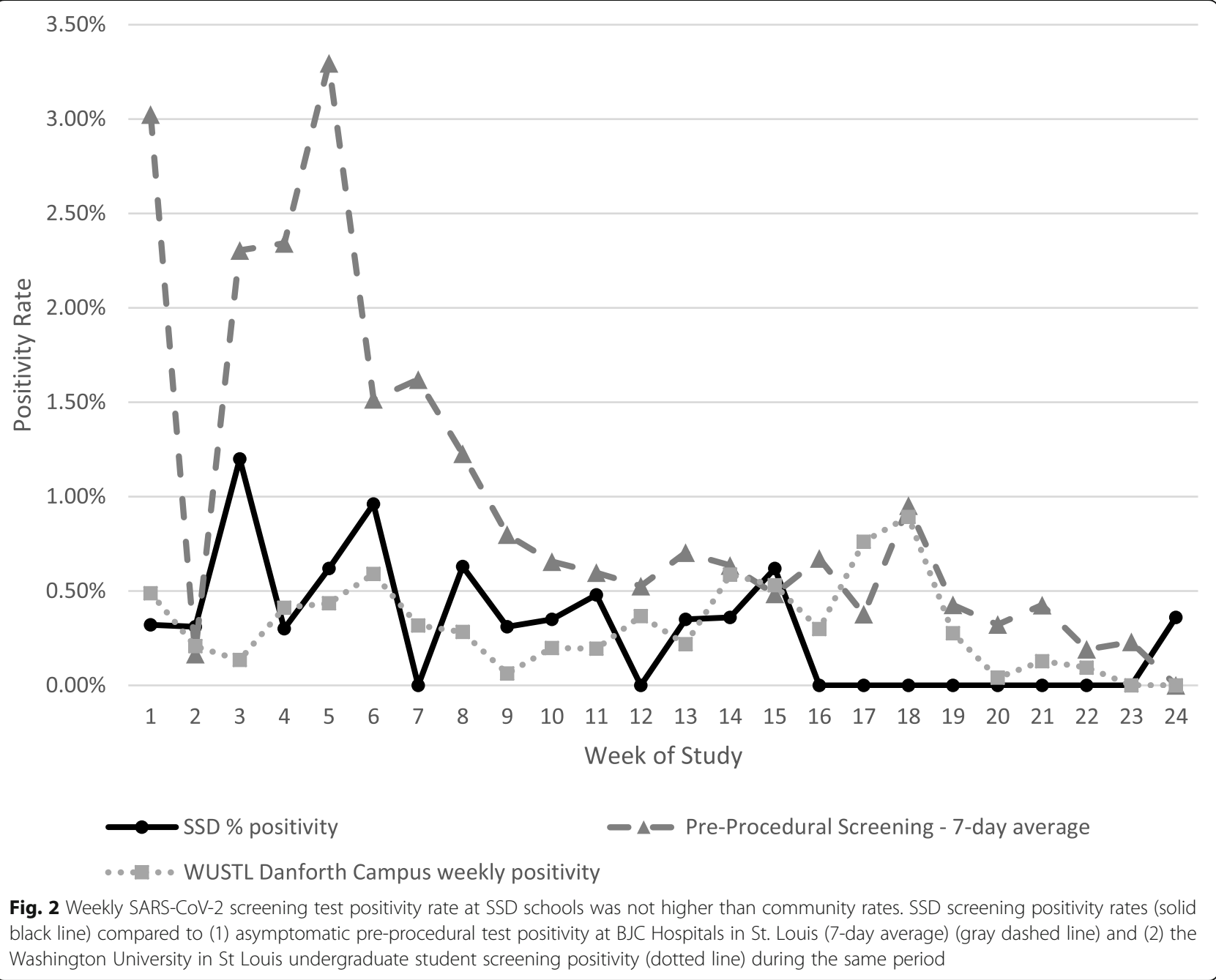

community rates. Furthermore, low rates of transmission were documented among participants with in-school exposures. As with other school studies conducted in schools for typically developing children, most SARSCoV-2 positive cases were found to result from transmission outside school $[8,9,16]$. In the context of a diagnostic testing regime, attending school in-person has been found to not be associated with an increased likelihood of a positive SARS-CoV-2 test [17].

Our screening testing identified half of the staff SARSCoV-2 infected cases compared to the number of positive diagnostic tests outside the study, although about two thirds of staff participated in the study. A mandatory screening testing program for Washington University in St. Louis undergraduate students during the same time period also identified nearly half of all known cases [18].

As staff and students were instructed to stay at home when ill, our SSD screening tests should have identified mostly asymptomatic or pre-symptomatic cases. However, when interviewing those who tested positive, many identified COVID-19 symptoms that they misattributed to other causes, such as allergies or sinus infections. Thus, encouraging self-report of mild symptoms with expanded access to convenient, no cost, on-site testing at schools could be an effective strategy to improve early diagnosis and quarantine, and minimize transmission.

As we and others have shown, screening testing may reduce in-school transmission and positivity rate by identifying and isolating cases where infection goes unnoticed or ignored [19]. Additionally, those staff who participated in screening testing were less likely to have COVID-19 during this study period. This result could be due to a number of factors, including study participants are more likely to follow mitigation strategies in and out of school and are less likely to participate in high risk behaviors. However, unless testing is required, voluntary participation is likely to wane over time due to many factors, including decreased sense of urgency as community case rates fall, lack of perceived necessity as individuals become vaccinated, or testing fatigue. More data on screening testing are 
needed to determine if mandatory school-wide or targeted testing approaches can lower school-based transmission even further in high-risk situations (e.g., caring for unvaccinated and unmasked individuals with IDD).

Although there were major differences in COVID-19 incidence across the St. Louis region at the beginning of the pandemic, at the onset of the study, COVID-19 was widespread with extremely high incidence (50-90 daily cases per 100,000). While positivity rates were similar across all schools, notable differences among in-person school attendance were observed, with lower rates of attendance in schools with a majority of Black/AfricanAmerican students, where disproportionately higher rates of infection were seen early in the pandemic. Other surveys have demonstrated that Black/African-Americans and Hispanic/Latino parents/guardians were less likely to have their children attend in-person school in Fall 2020 [20]. During the study, a slight increase of the percentage of in-person student attendance occurred, 58 to $65 \%$, across all six schools.

Mitigation strategies implemented at SSD schools alongside our screening testing may explain why in-school transmission was relatively low. SSD school staff attribute successful adoption of masking among students as a significant factor in keeping the positivity rates down and schools open. Beyond masks, adherence to additional mitigation strategies may have limited the in-school impact of COVID-19. However, some mitigation strategies, such as small class sizes and limiting students to small pods, may be less feasible when all students return to school fulltime. In addition, it is possible that individuals with greater commitment to safety may choose to return to inperson school as opposed to virtual learning, as others have observed [19], and greater challenges will occur when all children return. School mitigation strategies for children with disabilities, developed in collaboration with SSD staff, are available for dissemination to school administrators, teachers, and parents/guardians at our Safe Return to School for All website [21].

\section{Limitations}

Our study has several limitations. First, participation in screening testing was voluntary and may be biased to include individuals with greater adherence to safety protocols, and therefore, they may have been less likely to test positive than the general school population. Second, we were only able to determine transmission through interviews of positive cases and were not able to verify transmission through mandatory testing or sequencing, which may result in underestimating or misattributing in-school transmission rates. Additionally, we were unable to verify if the cases detected outside of the study were associated with in-school transmission, which may underestimate transmission rates if participants outside the study are systematically different than those who participated. Third, the study took place while in-person student school attendance was reduced both by hybrid scheduling (during the first 6 weeks) and entirely remote learning for $35-42 \%$ of children. This could have improved the effectiveness of the mitigation strategies and reduced overall exposures. Finally, most of the study's testing came before the potentially more transmissible SARS-CoV-2 Delta variant became widespread across the region. While the degree to which the Delta variant may impact transmission is unknown, masking and other currently deployed mitigation strategies will likely remain effective at reducing spread in these school settings.

\section{Conclusions}

During 24 weeks of screening testing staff and students at six SSD of St. Louis County schools coinciding with the winter 2020-21 peak of the COVID-19 pandemic, we found lower rates of SARS-CoV-2 in schools for children with IDD compared to community rates. Screening testing and school adherence to mitigation strategies for managing virus exposure, such as greater than expected masking, may have contributed to the low in-school transmission among participants and lack of increased SARS-CoV-2 positivity compared to community rates. Schools serving students with IDD may consider similar strategies for reducing transmission, including commitments to masking and other mitigation strategies, as well as periodic testing to monitor the effectiveness of COVID19 mitigation protocols. However, the recent emergence of the more transmissible SARS-CoV-2 Delta variant, which occurred only after the study reporting period, may warrant a cautious interpretation of our data and further study to assess effectiveness of mitigation strategies for this evolving pathogen.

\section{Supplementary Information}

The online version contains supplementary material available at https://doi. org/10.1186/s11689-021-09376-z.

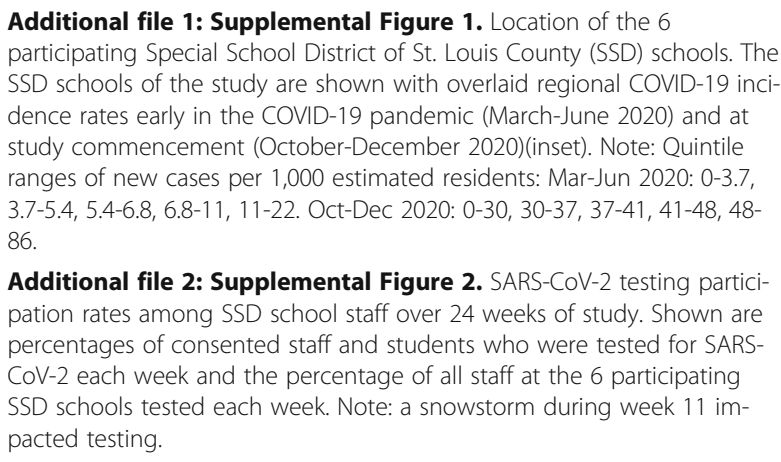
SSD schools of the study are shown with overlaid regional COVID-19 incidence rates early in the COVID-19 pandemic (March-June 2020) and at study commencement (October-December 2020)(inset). Note: Quintile ranges of new cases per 1,000 estimated residents: Mar-Jun 2020: 0-3.7, 3.7-5.4, 5.4-6.8, 6.8-11, 11-22. Oct-Dec 2020: 0-30, 30-37, 37-41, 41-48, 4886.

Additional file 2: Supplemental Figure 2. SARS-CoV-2 testing participation rates among SSD school staff over 24 weeks of study. Shown are percentages of consented staff and students who were tested for SARSCoV-2 each week and the percentage of all staff at the 6 participating SSD schools tested each week. Note: a snowstorm during week $11 \mathrm{im}$ pacted testing.

Additional file 3: Supplemental Figure 3. Total number of SARS-COV2 saliva tests performed per week as part of the study. Shown are numbers of weekly screening tests of all participants who were tested for 
SARS-CoV-2 and the weekly screening tests of students at the 6 participating SSD schools. Note: a snowstorm during week 11 impacted testing. Additional file 4: Supplemental Table 1. Study participation and testing by week.

\section{Acknowledgements}

The COMPASS-T project is a joint partnership between the Washington University in St. Louis Intellectual and Developmental Disabilities Research Center (WUIDDRC), the University of Missouri-Kansas City Institute of Human Development, the Kennedy Krieger Institute in Maryland, and the Special School District of St. Louis County (SSD) in Missouri. Other key collaborators include the Brown School Evaluation Center, the Health Communication Research Laboratory, and the Institute for Informatics at Washington University. This work is supported by the National Institutes of Health through the Rapid Acceleration of Diagnostics - Underserved Populations (RADx-UP) Program (P5OHD103525-01S1).

We thank the Genome Technology Access Center at the McDonnell Genome Institute of the Washington University School of Medicine for running the SARS-CoV-2 saliva testing, as well as the Department of Pathology and Immunology for access to their CAP/CLIA laboratory and their expertise in development of the saliva SARS-CoV-2 test. We also thank Steven Lawrence for access to the Washington University in St Louis undergraduate screening data.

\section{The COMPASS-T Study Group:}

Megan Baldenweck²; Kelly Bonoㄹ; Victor B. Brodsky, MDं Charlene A. Caburnay, PhD, MPH${ }^{7}$; John N. Constantino, $\mathrm{MD}^{8}$; Nikole Lobb Dougherty, $\mathrm{MA}^{7}$; James M. Dubois, $\mathrm{PhD}^{3}$; Stephanie A. Fritz, MD, MSCl${ }^{2}$; George S. Gotto IV, PhD ; Adwoa Imbeah ${ }^{2}$; Luther G. Kalb, PhD ${ }^{10}$; Jingxia Liu, PhD ${ }^{11}$; Brett B. Maricque, $\mathrm{PhD}^{5}$; Virginia R. McKay, PhD; Linda S. Myers, EdD ${ }^{10}$; Timothy J. Poor $^{7}$; Byron J. Powell, PhD ${ }^{9}$; Nancy B. Mueller, MPH'; Bradley L. Schlaggar, $\mathrm{MD}, \mathrm{PhD}^{10}$; Ann Schmidt, $\mathrm{MPH}^{7}$; Elsa Snider, $\mathrm{MPH}^{7}$; Matthew C. Traughber, $\mathrm{PhD}^{12}$; Maureen van Stone, JD, MS ${ }^{10}$; Liz Vestal, LMSW'; Myisha WilcherRoberts, $\mathrm{MA}^{7}$

7 Brown School of Social Work, Washington University in St. Louis, St. Louis, $\mathrm{MO}$

8 Department of Psychiatry, Washington University in St. Louis, St. Louis, MO 9 Institute for Human Development, University of Missouri-Kansas City, Kansas City, MO

10 Kennedy Krieger Institute, Baltimore, MD

11 Department of Surgery, Washington University in St. Louis, St. Louis, MO 12 Division of Evaluation and Research, Special School District of St. Louis County, MO

\section{Authors' contributions}

Drs. Gurnett and Newland conceptualized and designed the study, analyzed and interpreted data, supervised data collection, and critically reviewed and revised the manuscript for important intellectual content. Mr. Sherby drafted the initial manuscript, acquired data, analyzed the data, interpreted the data, and critically revised the manuscript for important intellectual content. Mr. Walsh acquired data, analyzed the data, interpreted the data, and revised the manuscript for important intellectual content. Drs. Lai and Neidich conceptualized and designed the study, analyzed and interpreted data, and critically reviewed and revised the manuscript for important intellectual content. Drs. Balls-Berry and Morris and Mr. Head conceptualized and designed the study and critically reviewed and revised the manuscript for important intellectual content. Dr. Prener analyzed and interpreted data and critically reviewed and revised the manuscript for important intellectual content. All authors approved the final manuscript as submitted and agree to be accountable for all aspects of the work.

\section{Funding}

Research reported in this publication was funded by the Eunice Kennedy Shriver National Institute of Child Health and Human Development of the National Institutes of Health under Award number 3P50HD103525-01S1 to the Intellectual and Developmental Disabilities Research Center at Washington University and the Washington University Institute of Clinical and Translational Sciences Award number UL1TR002345 from the National Center for Advancing Translational Sciences (NCATS). The content is solely the responsibility of the authors and does not necessarily represent the official views of the National Institutes of Health.

\section{Availability of data and materials}

Deidentified individual participant data (including data dictionaries) will be made available, in addition to study protocols, the statistical analysis plan, and the informed consent form. The data will be made available upon publication to researchers who provide a methodologically sound proposal for use in achieving the goals of the approved proposal. Proposals should be submitted to gurnettc@wustl.edu.

\section{Declarations}

\section{Ethics approval and consent to participate}

This study was approved by the Washington University in St. Louis Institutional Review Board (IRB) and individuals provided consent prior to participation. Prior to enrollment, this study was registered at ClinicalTrials. gov on September 25, 2020, identifier NCT04565509, titled Supporting the Health and Well-being of Children with Intellectual and Developmental Disability During COVID-19 Pandemic.

\section{Consent for publication}

Not applicable.

\section{Competing interests}

The authors have no competing interests relevant to this article to disclose.

\section{Author details}

${ }^{1}$ Department of Neurology, Division of Pediatric and Developmental Neurology, Washington University in St. Louis, 660 S. Euclid Avenue Campus, Box 8111, St. Louis, MO 63110, USA. ²Department of Pediatrics, Division of Pediatric Infectious Diseases, Washington University in St. Louis, St. Louis, MO, USA. ${ }^{3}$ Department of Medicine, Washington University in St. Louis, St. Louis, MO, USA. ${ }^{4}$ Department of Pathology and Immunology, Washington University in St. Louis, St. Louis, MO, USA. ${ }^{5}$ Department of Neurology, Division of Memory and Aging, Washington University in St. Louis, St. Louis, MO, USA. 'Department of Genetics, Washington University in St. Louis, St. Louis, MO, USA. ${ }^{7}$ Department of Sociology and Anthropology, Saint Louis University, St. Louis, MO, USA.

Received: 15 July 2021 Accepted: 3 August 2021

Published online: 01 September 2021

\section{References}

1. The condition of education: students with disabilities: National Center for Education Statistics, 2020.

2. American Academy of Pediatrics: COVID-19 Guidance for Safe Schools [online]. Available at: https://services.aap.org/en/pages/2019-novel-corona virus-covid-19-infections/clinical-guidance/covid-19-planning-considerationsreturn-to-in-person-education-in-schools/.

3. Neece C, McIntyre LL, Fenning R. Examining the impact of COVID-19 in ethnically diverse families with young children with intellectual and developmental disabilities. J Intellect Disabil Res. 2020;64(10):739-49. https:// doi.org/10.1111/jir.12769.

4. Woodman AC, Mawdsley HP, Hauser-Cram P. Parenting stress and child behavior problems within families of children with developmental disabilities: transactional relations across 15 years. Res Dev Disabil. 2015;36C: 264-76. https://doi.org/10.1016/j.ridd.2014.10.011.

5. Neece CL, Green SA, Baker BL. Parenting stress and child behavior problems: a transactional relationship across time. Am J Intellect Dev Disabil. 2012; 117(1):48-66. https://doi.org/10.1352/1944-7558-117.1.48.

6. Centers for Disease Control and Prevention COVID-19 Guidance: People at Increased Risk; And Other People Who Need to Take Extra Precautions [online]. Available at: https://www.cdc.gov/coronavirus/2019-ncov/needextra-precautions/people-with-medical-conditions.html.

7. Gleason JRW, Fossi A, Blonsky H, Tobias J, Stephens M. The devastating impact of COVID-19 on individuals with intellectual disabilities in the United States. NEJM Catal Innov Care Deliv. 2021. https://doi.org/10.1056/CAT.21. 0051.

8. Zimmerman KO, Akinboyo IC, Brookhart MA, Boutzoukas AE, McGann KA, Smith MJ, et al. Incidence and secondary transmission of SARS-CoV-2 infections in schools. Pediatrics. 2021;147(4):e2020048090. https://doi.org/1 0.1542/peds.2020-048090. 
9. Dawson P, Worrell MC, Malone S, Tinker SC, Fritz S, Maricque B, et al. Pilot investigation of SARS-CoV-2 secondary transmission in kindergarten through grade 12 schools implementing mitigation strategies - St. Louis County and City of Springfield, Missouri, December 2020. MMWR Morb Mortal Wkly Rep. 2021;70(12):449-55. https://doi.org/10.15585/mmwr.mm7012e4.

10. Centers for Disease Control and Prevention COVID-19 Guidance: Operational Strategy for K-12 Schools through Phased Prevention. U.S. Centers for Disease Control and Prevention (CDC), 2021.

11. The ABC Science Collaborative [online]. Available at: https://abcsciencecolla borative.org/.

12. Hershow RB, Wu K, Lewis NM, Milne AT, Currie D, Smith AR, et al. Low SARSCoV-2 transmission in elementary schools - Salt Lake County, Utah, December 3, 2020-January 31, 2021. MMWR Morb Mortal Wkly Rep. 2021; 70(12):442-8. https://doi.org/10.15585/mmwr.mm7012e3.

13. St. Louis County COVID-19 Dashboard [online]. Available at: https:// stlcorona.com/resources/covid-19-statistics/.

14. The tests were conducted pursuant to FDA Emergency Use Authorization EUA201725 (available at https://www.fda.gov/media/141538/download).

15. BJC Healthcare Pre-Procedure screening test results from Nov. 20, 2020 to May $28,2021$.

16. Leeb RT, Price S, Sliwa S, Kimball A, Szucs L, Caruso E, et al. COVID-19 trends among school-aged children - United States, March 1-September 19, 2020. MMWR Morb Mortal Wkly Rep. 2020;69(39):1410-5. https://doi.org/10.15585/ mmwr.mm6939e2

17. Hobbs CV, Martin LM, Kim SS, Kirmse BM, Haynie L, McGraw S, et al. Factors associated with positive SARS-CoV-2 test results in outpatient health facilities and emergency departments among children and adolescents aged < 18 years - Mississippi, September-November 2020. MMWR Morb Mortal Wkly Rep. 2020;69(50):1925-9. https://doi.org/10.15585/mmwr. mm6950e3.

18. Washington University in St. Louis Danforth Campus COVID-19 Dashboard [online]. Available at: https://covid19.wustl.edu/danforth-campus-covid-19dashboard/.

19. Varma JK, Thamkittikasem J, Whittemore K, Alexander M, Stephens DH, Arslanian K, et al. COVID-19 infections among students and staff in New York City public schools. Pediatrics. 2021;147(5):e2021050605. https://doi. org/10.1542/peds.2021-050605

20. Gilbert LK, Strine TW, Szucs LE, Crawford TN, Parks SE, Barradas DT, et al. Racial and ethnic differences in parental attitudes and concerns about school reopening during the COVID-19 pandemic - United States, July 2020. MMWR Morb Mortal Wkly Rep. 2020;69(49):1848-52. https://doi.org/10.1 5585/mmwr.mm6949a2.

21. Safe return to school for all [online]. Available at: http://sites.wustl.edu/sa fereturn.

\section{Publisher's Note}

Springer Nature remains neutral with regard to jurisdictional claims in published maps and institutional affiliations.

Ready to submit your research? Choose BMC and benefit from:

- fast, convenient online submission

- thorough peer review by experienced researchers in your field

- rapid publication on acceptance

- support for research data, including large and complex data types

- gold Open Access which fosters wider collaboration and increased citations

- maximum visibility for your research: over $100 \mathrm{M}$ website views per year

At BMC, research is always in progress.

Learn more biomedcentral.com/submissions 